\title{
Photochemically-mediated nickel-catalyzed synthesis of $N$-(hetero)aryl sulfamides
}

R. Thomas Simons, Georgia E. Scott, Anastasia L. Gant Kanegusuku and Jennifer L. Roizen*

Duke University, Department of Chemistry, Box 90346, Durham, NC, 27708-0354, USA

Corresponding Author - E-mail: j.roizen@duke.edu

Table of Contents/Abstract Graphic:
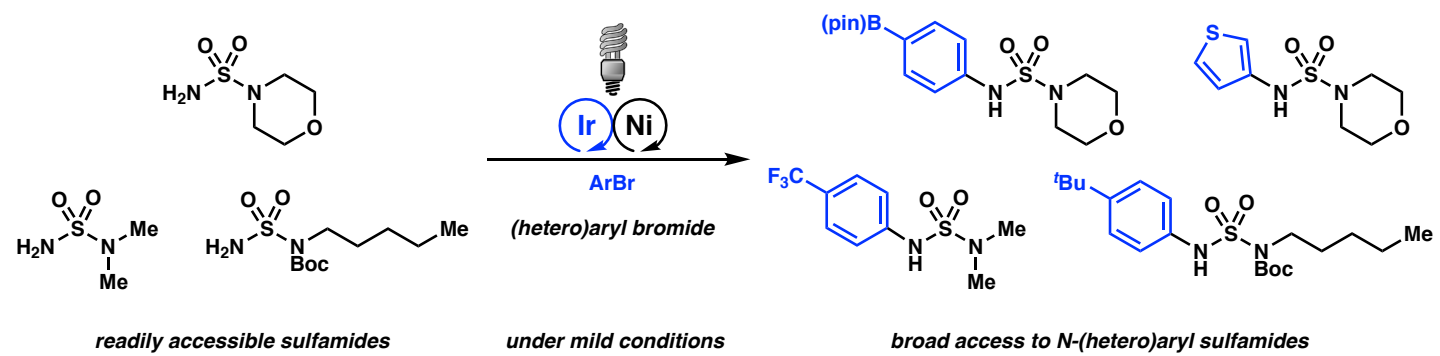

broad access to $\mathrm{N}$-(hetero)aryl sulfamides

ABSTRACT: A general method for the $N$-arylation of sulfamides with aryl bromides is described. The protocol leverages a dual-catalytic system of nickel and a photoexcitable iridium complex and proceeds at room temperature under visible light irradiation. Using these tactics, aryl boronic esters and aryl chlorides can be carried through the reaction untouched. Thereby, this method complements known Buchwald-Hartwig coupling methods for $N$-arylation of sulfamides.

\section{INTRODUCTION}

$N$-Aryl sulfamides are critical components of active pharmaceutical ${ }^{1}$ and agrochemical $^{2}$ agents (Figure 1). ${ }^{3,4}$ In drug discovery, sulfamides can be valuable analogues of sulfamate, sulfonamide, urea, carbamate, and amide functional groups. ${ }^{1 \text { a }}$ In reactions, $N, N$ '-disubstituted sulfamides are useful as chiral auxiliaries, ${ }^{5}$ as organocatalysts, ${ }^{6}$ as reagents to promote dehydration, ${ }^{7}$ as precursors to sterically encumbered carbon-carbon bonds ${ }^{8}$ and as directing groups for $\mathrm{C}-\mathrm{H}$ functionalization processes. ${ }^{9}$ Despite the potential of this valuable functional group, 
sulfamides may be underutilized due to limitations in practical methods for their preparation. ${ }^{10}$ 11,12

Figure 1. $N$-heteroaryl sulfamides are important FDA-approved drugs and therapeutic targets

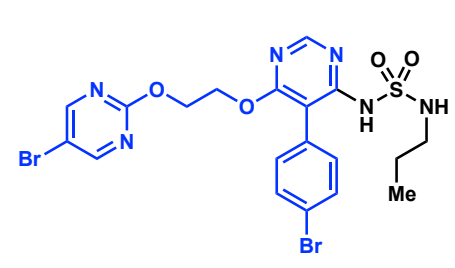

macitentan (brand name: Opsumit) FDA approved treatment for pulmonary arterial hypertention

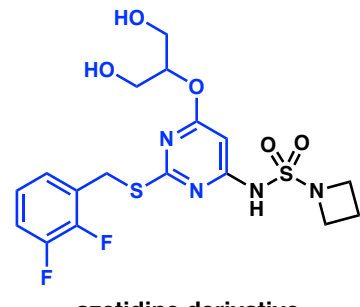

azetidine derivative patented as a potential
chemokine receptor modulator

To date, approaches to prepare $\mathrm{N}$-(hetero)aryl sulfamides rely on $\mathrm{N}-\mathrm{S}$ bond-forming reactions that involve the nucleophilic addition of amines to $\mathrm{SO}_{2}$ sources (not depicted), ${ }^{12,13}$ or on $\mathrm{C}-\mathrm{N}$ bond-forming strategies (Scheme 1). These direct methods for $\mathrm{C}-\mathrm{N}$ bond formation have been primarily limited to nucleophilic substitution reactions (Scheme 1A), copper-mediated ChanLam coupling processes that transform sulfamoyl azides (Scheme 1B), ${ }^{14}$ and Buchwald-Hartwig amination conditions that are palladium-mediated (Scheme 1C). ${ }^{15,16,17}$

Recently, room temperature Buchwald-Hartwig reaction protocols have emerged that are photochemically-driven and nickel-catalyzed. ${ }^{18,} 19$ These mild conditions are complementary to palladium-mediated protocols, representing one of the most general platforms in terms of the breadth of arenes tolerated in $N$-arylation processes. ${ }^{18 a}$ Additionally, nickel-catalyzed photochemically-driven conditions engage a broader range of nucleophilic coupling partners in efficient $\mathrm{C}-\mathrm{N}$ bond-forming reactions. ${ }^{19}$ Accordingly, we anticipated that these photo-driven, nickel-catalyzed processes would afford an efficient, robust, and complementary strategy to access valuable $N$-(hetero)aryl sulfamides. Herein disclosed is the first photochemically-mediated, nickel-catalyzed method to access $N$-(hetero)aryl sulfamides. 
(A) Nucleophilic aromatic substitution reactions with sulfamide nucleophiles

c.f. Bolli and co-workers, 2012

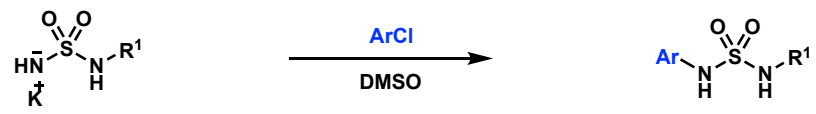

(B) Chan-Lam cross-coupling reactions

C.f. Kim and co-workers, 2019

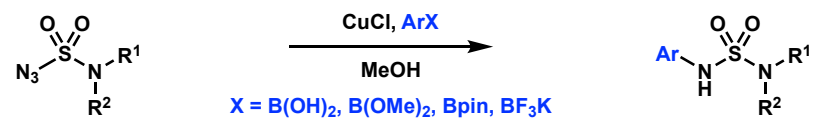

(C) Palladium-mediated cross-coupling reactions

c.f. Alcaraz and co-workers, 2004

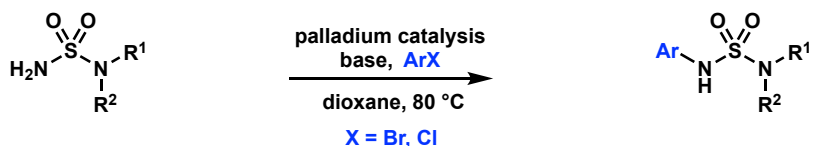

(D) This investigation: sulfamides from mild, Ni/lr dual catalysis strategy<smiles>[R]N(C)S(N)(=O)=O</smiles>
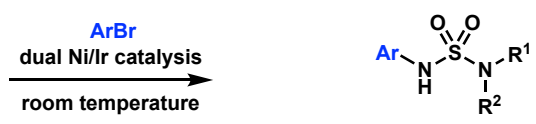

Scheme 1. Recent advances allow for diverse and complementary strategies for the synthesis of $N$-(hetero)aryl sulfamides

\section{Results and Discussion}

$\mathrm{We}^{13}$ and others ${ }^{18 d}$ have observed that, relative to electron-deficient arylbromides, electronrich arylbromides can be more challenging electrophiles when employing nickel-mediated crosscoupling technologies. Accordingly, we optimized the reactions of sulfamide 1a with electrondeficient 4-(trifluoromethyl)bromobenzene and electron-rich 4-(tert-butyl)bromobenzene concurrently (Table 1).

Relying on previously established conditions for the arylation of sulfamate esters, ${ }^{13}$ sulfamide 1a reacts with 4-(trifluoromethyl)bromobenzene to afford $\mathrm{N}$-aryl sulfamide 3a in quantitative yield (Table 1, entry 1). This synthetic protocol can transform aryl chloride and iodide electrophiles, albeit in slightly diminished yields (entries 2-3). Unsurprisingly, sulfamide 1a reacts with 4-(tert-butyl)bromobenzene inefficiently (entries 4-5). Consistent with previous 
observations, ${ }^{13,18 \mathrm{~d}}$ higher turnover numbers can be achieved when 4,4'-di-tert-butyl-2,2'-dipyridyl (dtbbpy) is employed as a ligand for nickel (entry 6).

To our surprise, the efficiency of this reaction improves substantially when it is run in absolute ethanol, or with ethanol as a co-solvent (entries 7-8). Importantly, the solvent and the aryl bromide do not engage in undesirable $\mathrm{C}-\mathrm{O}$ coupling processes, as the predicted products of these processes are not detected. Unfortunately, the reaction efficiency drops in the presence of 100 equiv of water (entry 9). When we assessed a single solvent from each of seven solubility clusters, ${ }^{20}$ the reaction was less efficient in these other solvents (entries 10-15). The advantages of ethanol were isolated to reactions engaging this more electron-rich aryl bromide, and did not translate to the reaction of 4-(trifluoromethyl)bromobenzene (entries 16-17). This synthetic protocol can be used to transform aryl iodide electrophiles but does not transform electron-rich aryl chlorides in synthetically useful efficiencies (entries 18-19). Control experiments confirm that nickel, photocatalyst, and light are critical to the success of both of the optimized cross-coupling protocols (see supporting information for details).

Table 1. Optimization informs distinct conditions for electron-deficient and electron-rich aryl bromides

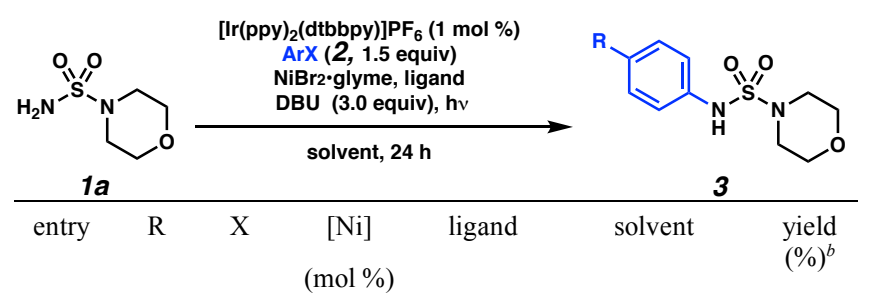

\begin{tabular}{lllllll}
\hline 1 & $\mathrm{CF}_{3}$ & $\mathrm{Br}$ & 5 & - & $\mathrm{MeCN}$ & $>98^{c}$ \\
2 & $\mathrm{CF}_{3}$ & $\mathrm{I}$ & 5 & - & $\mathrm{MeCN}$ & 79 \\
3 & $\mathrm{CF}_{3}$ & $\mathrm{Cl}$ & 5 & - & $\mathrm{MeCN}$ & 43 \\
\hline 4 & ${ }^{t} \mathrm{Bu}$ & $\mathrm{Br}$ & 5 & - & $\mathrm{MeCN}$ & 32 \\
5 & ${ }^{t} \mathrm{Bu}$ & $\mathrm{Br}$ & 10 & - & $\mathrm{MeCN}$ & 33 \\
6 & ${ }^{t} \mathrm{Bu}$ & $\mathrm{Br}$ & 10 & dtbbpy & $\mathrm{MeCN}$ & 47 \\
7 & ${ }^{t} \mathrm{Bu}$ & $\mathrm{Br}$ & 10 & dtbbpy & EtOH & $89^{c}$ \\
8 & ${ }^{t} \mathrm{Bu}$ & $\mathrm{Br}$ & 10 & dtbbpy & $9: 1 \mathrm{MeCN}:$ & 90 \\
& & & & & EtOH &
\end{tabular}




\begin{tabular}{|c|c|c|c|c|c|c|}
\hline 9 & ${ }^{t} \mathrm{Bu}$ & $\mathrm{Br}$ & 10 & dtbbpy & $\begin{array}{l}\text { EtOH with } \mathrm{H}_{2} \mathrm{O} \\
\text { (100 equiv) }\end{array}$ & 6 \\
\hline 10 & ${ }^{t} \mathrm{Bu}$ & $\mathrm{Br}$ & 10 & dtbbpy & $\mathrm{MeOH}$ & 76 \\
\hline 11 & ${ }^{t} \mathrm{Bu}$ & $\mathrm{Br}$ & 10 & dtbbpy & ${ }^{i} \mathrm{PrOAc}$ & 7 \\
\hline 12 & ${ }^{t} \mathrm{Bu}$ & $\mathrm{Br}$ & 10 & dtbbpy & $\mathrm{CH}_{2} \mathrm{Cl}_{2}$ & 0 \\
\hline 13 & ${ }^{t} \mathrm{Bu}$ & $\mathrm{Br}$ & 10 & dtbbpy & DMSO & 32 \\
\hline 14 & ${ }^{t} \mathrm{Bu}$ & $\mathrm{Br}$ & 10 & dtbbpy & acetone & 35 \\
\hline 15 & ${ }^{t} \mathrm{Bu}$ & $\mathrm{Br}$ & 10 & dtbbpy & $\begin{array}{l}\text { 2-methyl } \\
\text { tetrahydrofuran }\end{array}$ & 23 \\
\hline 16 & $\mathrm{CF}_{3}$ & $\mathrm{Br}$ & 5 & - & $\mathrm{EtOH}$ & 70 \\
\hline 17 & $\mathrm{CF}_{3}$ & $\mathrm{Br}$ & 5 & - & $\mathrm{MeOH}$ & $81^{c}$ \\
\hline 18 & ${ }^{t} \mathrm{Bu}$ & I & 10 & dtbbpy & $\mathrm{EtOH}$ & 81 \\
\hline 19 & ${ }^{t} \mathrm{Bu}$ & $\mathrm{Cl}$ & 10 & dtbbpy & $\mathrm{EtOH}$ & 7 \\
\hline
\end{tabular}

${ }^{a}$ General reaction conditions: sulfamide $\mathbf{1 a}\left(1.0\right.$ equiv), aryl halide $\mathbf{2}\left(1.5\right.$ equiv), $\mathrm{NiBr}_{2} \bullet \mathrm{glyme},\left[\operatorname{Ir}(\mathrm{ppy})_{2}(\mathrm{dtbbpy})\right] \mathrm{PF} 6$ (1 mol \%), DBU (3.0 equiv), and ligand (4 mol \%) in indicated solvent $(0.25 \mathrm{M})$ with stirring and irradiation between two $34 \mathrm{~W}$ blue Kessil lamps for 24 h. ${ }^{b}$ NMR yield using an internal standard of 2,3,5,6-tetrachloronitrobenzene. ${ }^{c}$ Isolated yield.

These dual catalyzed processes offer complementary reactivity profiles to those available through palladium-mediated Buchwald-Hartwig reactions. We have employed the developed ligand-free conditions to recapitulate palladium-mediated $\mathrm{C}-\mathrm{N}$ bond-forming reactions to access arylated $\mathbf{3 c}$ and $\mathbf{3 d} .{ }^{16 a}$ The developed nickel-mediated transformations furnish these products with increased yields, relative to those documented using a known palladium-mediated protocol, ${ }^{16 \mathrm{a}}$ suggesting that this nickel-mediated approach is worthy of concurrent investigation in the course of synthetic campaigns. Given our interest in functionalized pyridines, ${ }^{21}$ we were pleased to find that bromopyridines were effective arylating agents using the disclosed protocol. Furthermore, this dual catalytic reaction manifold can transform aryl bromides, without engaging either $\mathrm{C}\left(\mathrm{sp}^{2}\right)-\mathrm{B}$ (3e) and $\mathrm{C}\left(\mathrm{sp}^{2}\right)-\mathrm{Cl}(\mathbf{3 f}-\mathbf{g})$ bonds to afford products with useful synthetic handles for further functionalization.

The reaction arylates $N, N$-disubstituted sulfamides in synthetically useful yields, with examples including $N$-morpholino 1a, $N, N$-dimethylated $\mathbf{1 b}$, and $N$-carbonyl- $N$-alkylated 1c 
sulfamides. In this arylation reaction, $N$-carbonyl- $N$-alkylated sulfamides, such as 1c, are appropriate surrogates for sterically deshielded $N$-monosubstituted sulfamides, which are not prone solely to monoarylation reactions under the developed protocols.

Scheme 2. Photochemically-mediated nickel-catalyzed conditions engage a variety of electron-deficient aryl bromides and sulfamides
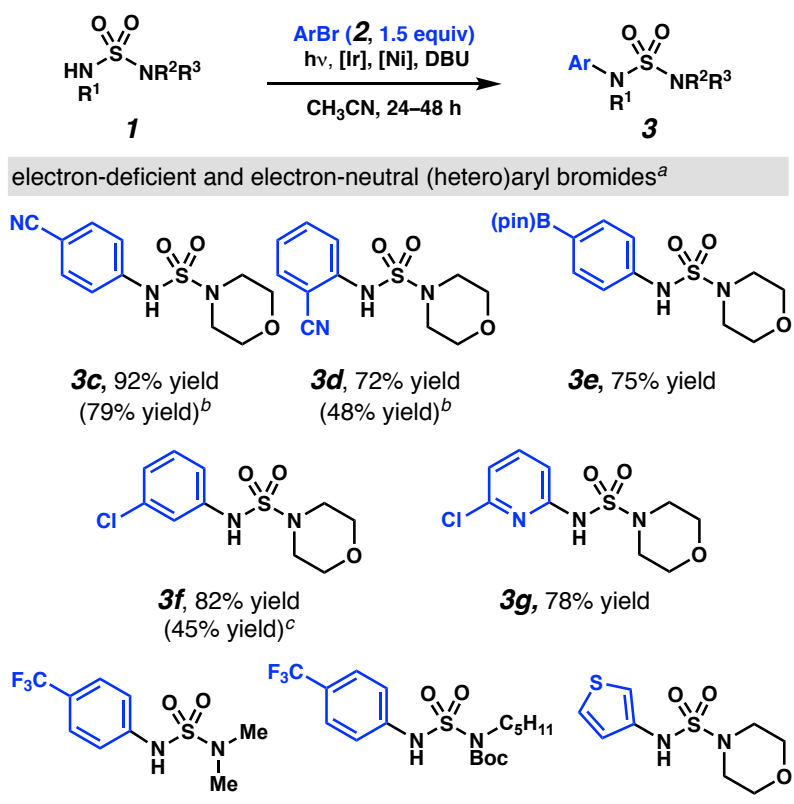

$\mathbf{3 h},>98 \%$ yield $\quad \mathbf{3 i}, 80 \%$ yield $\quad \mathbf{3 j}, \mathbf{3 7 \%}$ yield

${ }^{a}$ General conditions: sulfamide 1 (1.0 equiv), (hetero)aryl bromide (1.5 equiv), [ $\left.\operatorname{Ir}(\mathrm{ppy})_{2}(\mathrm{dtbbpy})\right] \mathrm{PF}_{6}(1 \mathrm{~mol} \%)$, $\mathrm{NiBr}_{2} \bullet \mathrm{glyme}(5 \mathrm{~mol} \%)$, and DBU (3.0 equiv) in MeCN (0.25 M) with stirring between two 34W blue Kessil lamps for $24-48$ h. ${ }^{b}$ Isolated yield through a palladium-mediated cross-coupling reaction. ${ }^{16 a} c$ Isolated yield when prepared from subjecting morpholinyl sulfamoyl chloride ${ }^{22}$ following literature conditions. $^{23}$

In general, electron-deficient aryl bromides $N$-arylate sulfamides in good to excellent yields (3c-3i). By contrast, in acetonitrile, some electron-rich aryl bromides react with modest efficiency (c.f. Table 1, entry 4; Scheme 2, $\mathbf{2 j}$ ). In spite of this limitation, a thiophene (2j) can be installed onto a sulfamide in modest yield. This result suggests that this protocol overcomes the common tendency of nickel catalysts to engage in $\mathrm{C}-\mathrm{S}$ bond activation, ${ }^{24}$ or to be deactivated upon reaction with sulfur. 
Fortunately, with the use of EtOH as a solvent and inclusion of a ligand, the protocol can transform a similar range of sulfamide substrates and allows the efficient cross-coupling of electronically-varied (hetero)aryl bromides. Specifically, electron-rich para- and meta-substituted $N$-aryl sulfamides $\mathbf{3 k}$, $3 \mathbf{l}$ were synthesized with similar or improved yields relative to those reportedly isolated upon reaction of morpholinyl sulfamyl chloride with anilines. As anticipated, under these conditions, aryl bromides can react, without engaging either $\mathrm{C}\left(\mathrm{sp}^{2}\right)-\mathrm{B}(\mathbf{3 e})$ and $\mathrm{C}\left(\mathrm{sp}^{2}\right)-$ $\mathrm{Cl}(\mathbf{3 m})$ bonds to afford products with useful synthetic handles for further functionalization. Furthermore, these conditions can be used to install heteroaryl groups including a pyrimidine (3n). Unfortunately, the installation of more conjugated benzothiazole, tert-butyl indole-1-carboxylate, quinoline, and 2-methylnaphthalene moieties has proven less efficient (c.f. 3o-3r). By comparison, while $13 \%$ yield of the quinoline analogue $\mathbf{3 q}$ can be isolated under the developed nickel/iridium-mediated conditions, its preparation has proven more efficient by way of nucleophilic substitution on sulfur(VI), which proceed in $57 \%$ yield. ${ }^{13 b}$

In EtOH, some variations in sulfamide substitution are well tolerated. The reaction engages $\mathrm{N}, \mathrm{N}$-disubstituted sulfamides in synthetically useful yields, with examples including $\mathrm{N}$ morpholino 1a, $N$-carbonyl- $N$-alkylated 1c, and $N, N$-dimethylated $\mathbf{1 b}$ sulfamides. In this arylation reaction, $N$-carbonyl- $N$-alkylated sulfamides, such as 1c, are appropriate surrogates for sterically deshielded $N$-monosubstituted sulfamides, which can be forced to engage in monoarylation reactions when larger aryl bromide electrophiles are employed, albeit in low efficiency. Notably, this protocol does not provide efficient access to a tetrasubstituted sulfamide $\mathbf{3 u}$. 
Scheme 3. Photochemically-mediated nickel-catalyzed conditions engage a variety of sulfamides and electron-rich aryl bromides
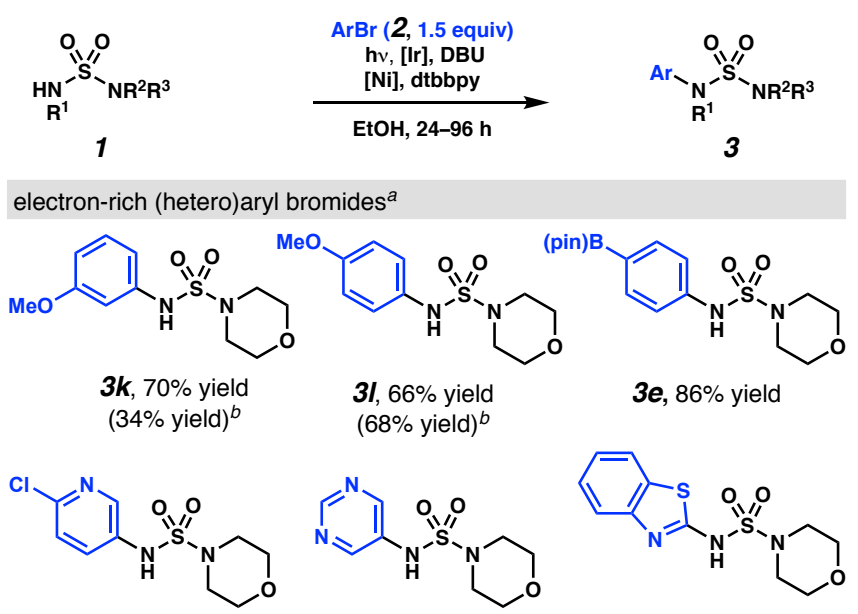

$3 m, 78 \%$ yield

$3 n, 77 \%$ yield

$30,23 \%$ yield $(62 \% \text { yield })^{b}$
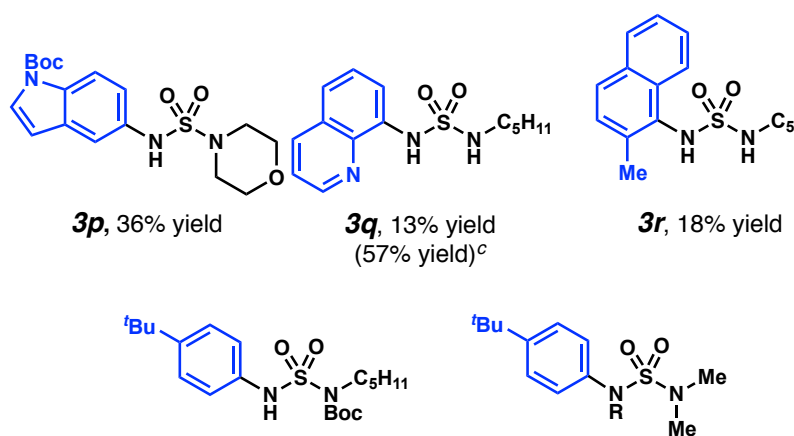

$3 s, 85 \%$ yield

$$
3 \boldsymbol{t}, \mathbf{R}=\mathbf{H}, 85 \% \text { yield }
$$

$\mathbf{3 u}, \mathbf{R}=\mathbf{M e}, 6 \%$ yield

${ }^{a}$ General conditions: sulfamide 1 (1.0 equiv), (hetero)aryl bromide (1.5 equiv), [ $\left.\operatorname{Ir}(\mathrm{ppy}) 2(\mathrm{dtbbpy})\right] \mathrm{PF}_{6}(1 \mathrm{~mol} \%)$, $\mathrm{NiBr}_{2} \bullet$ glyme (10 mol \%), dtbbpy (4 mol \%) and DBU (3.0 equiv) in EtOH (0.25 M) with stirring between two $34 \mathrm{~W}$ blue Kessil lamps for $24-96$ h. ${ }^{b}$ Isolated yield when prepared from $N, N$-dichlorosulfamide.$^{25}{ }^{c}$ Isolated yield when prepared from sulfamic acid. ${ }^{13 b}$

\section{Conclusion}

We have developed a new catalytic method for sulfamide $N$-(hetero)arylation. This protocol offers several attributes, as it proceeds under mild conditions, and employs a variety of readily available substrates and reagents that complements the range that may be used under palladium-mediated Buchwald-Hartwig reaction conditions. The developed photo-driven nickelmediated tactics can be employed with (hetero)aryl bromide, iodide, and chloride electrophiles. 
Fortunately, owing to the higher reaction efficiency with (hetero)aryl bromides, aryl boronic esters and aryl chlorides can be carried through the reaction untouched, so these useful synthetic handles can be retained for further synthetic manipulation. Owing to these attributes, this method extends chemists' ability to use a sulfamide in the most versatile step a medicinal chemistry campaign, the "production step." ${ }^{26}$ Moreover, it broadens the synthetic access to $N$-(hetero)aryl sulfamides, which are of increasing pharmacological interest.

\section{Conflicts of interest}

The authors declare no conflicts of interest.

\section{Acknowledgments}

Funding was provided by the National Institutes of Health (R35GM128741-01). Characterization data were obtained on instrumentation secured by funding from the NSF (CHE-0923097, ESIMS, George Dubay, the Duke Dept. of Chemistry Instrument Center), or the NSF, the NIH, NHMI, the North Carolina Biotechnology Center and Duke (Duke Magnetic Resonance Spectroscopy Center). We thank Dr. Peter Silinski (Duke University) for performing high-resolution mass spectrometry.

\section{Supplementary Data}

Supplementary data to this article can be found online at insert hyperlink to SI here.

\section{References and Endnotes}

${ }^{1}$ For recent reviews that highlight sulfamide-containing therapeutic targets, see: (a) Reitz A. B.; Smith G. R.; Parker, M. H. The role of sulfamide derivatives in medicinal chemistry: a patent review (2006-2008). Expert Opin. Ther. Pat. 2009, 19, 1449-1453. (b) Scott, K. A.; Njardarson, J. T. Analysis of US FDA-Approved Drugs Containing Sulfur Atoms. Top. Curr. Chem. (Z), 2018, 376, 5.

${ }^{2}$ Devendar, P.; Yang, G.-F. Sulfur-Containing Agrochemicals. Top. Curr. Chem. (Z), 2017, $375,82$.

3 For $\mathrm{S}_{\mathrm{N}} \mathrm{Ar}$ approaches to prepare Macitentan, see: (a) Bolli, M.; Boss, C.; Treiber, A. 4PYRIMINIDINESULFAMIDE DERIVATIVE. World IP Org. WO 2009/024906 A1. February 26, 2009. (b) Bolli, 
M. H.; Boss, C.; Binkert, C.; Buchmann, S.; Bur, D.; Hess, P.; Iglarz, M.; Meyer, S.; Rein, J.; Rey, M.; Trieber, A.; Clozel, M.; Fischli, W.; Weller, T. The discovery of N-[5-(4-Bromophenyl)-6-[2-[(5-bromo-2pyrimidinyl)oxy]ethoxy]-4-pyrimidinyl- $N$ '-propylsulfamide (Macitentan), an Orally Active, Potent Dual Endothelin Receptor Antagonist. J. Med. Chem. 2012, 55, 17, 7849-7861.

${ }^{4}$ For palladium-catalyzed cross-coupling approaches to prepare the depicted chemokine receptor modulator, see: Cheshire, D. R.; Cox, R. J.; Meghani, P.; Preston, C. F.; Smith, N. M.; Stonehouse, J. P. PYRIMIDINE SULPHONAMIDE DERIVATIVES AS CHEMOKINE RECEPTOR MODULATORS. World IP Org. WO 2006/024823 A1. March 9, 2006.

${ }^{5}$ Ahn, K. H.; Yoo, D. J.; Kim, J. S. Asymmetric aldol reactions employing a cyclic sulfamide chiral auxillary. Tetrahedron Lett. 1992, 33, 6661-6664.

${ }^{6}$ Zhang, X.-J.; Liu, S.-P.; Li, X.-M.; Yan, M.; Chan, A. S. C. Highly enantioselective conjugate addition of aldehydes to nitroolefins catalyzed by chiral bifunctional sulfamides. Chem. Commun. 2009, 833-836.

${ }^{7}$ For applications of Burgess reagent to the synthesis of sulfamides, including tetrasubstituted sulfamides, see: Nicolaou, K. C.; Snyder, S. A.; Longbottom, D. A.; Nalbandian, A. Z.; Huang, X. New uses for the Burgess reagent in chemical synthesis: Methods for the facile and stereoselective formation of sulfamidates, glycosylamines, and sulfamides. Chem. Eur. J. 2004, 10, 5581-5606.

${ }^{8}$ (a) Movassaghi, M.; Ahmad, O. K.; Lathrop, S. P. Directed Heterodimerization: Stereocontrolled Assembly via Solvent-Cages Unsymmetrical Diazene Fragmentation. J. Am. Chem. Soc. 2011, 133, 13002-13005. (b) Lathrop, S. P.; Movassaghi, M. Application of diazene-directed fragment assembly to the total synthesis and stereochemical assignment of (+)-desmethyl-meso-chimonanthine and related heterodimeric alkaloids. Chem. Sci. 2014, 5, 333-340. (c) Kim, J.; Movassaghi, M. Biogenetically-Inspired Total Synthesis of Epidithiodiketopiperazines and Related Alkaloids. Acc. Chem. Res. 2015, 48, 1159-1171.

${ }^{9}$ For pioneering reports, see: (a) Duhamel, T.; Matínez, M. D.; Sideri, I. K.; Muñiz, K. 1,3-Diamine Formation from an Interrupted Hofmann-Löffler reaction: Iodine Catalyst Turnover through Ritter-Type Amination. ACS Catal. 2019, 9, 7741-7745. (b) Short, M.; Shehata, M. F.; Sanders, M.; Roizen, J. L. Chem. Sci. 2019, 11, $217-223$.

${ }^{10}$ For a review highlighting strategies to prepare and employ sulfamic acid derivatives, see: Spillane, W. Sulfamic Acid and Its $N$ - and $O$-Substituted Derivatives. Chem. Rev. 2014, 114, 2507-2586. 
${ }^{11}$ For preparations of $\mathrm{N}$-alkyl substituted sulfamides using highly reactive chloroisocyannate, see: (a) Iso, Y.; Irie, T.; Iwaki, T.; Kii, M.; Sendo, Y.; Motokawa, K.; Nishitani, Y. Synthesis and Modification of a Novel 1b-Methyl Carbapenem Antibiotic, S-466. J. Antibiot. 1996, 49, 478-484. (b) Abdaoui, M.; Dewynter, G.; Aouf, N.; Favre, G.; Morere, A.; Montero, J.-L. A New Family of Potential Oncostatics: 2-Chloroethylnitrosulfamides (CENS)-I. Synthesis, Structure, and Pharmacological Evaluation (Preliminary Results). Bioorg. Med. Chem. 1996, 4, 1227-1235. (c) Kavalek, J.; Kralikova, U.; Machacek, V.; Sedlak, M.; Sterba, V. kinetics and Mechanism of Solvolysis of N-Aryl Sulfuric Siamides. Collect. Czech. Chem. Commun. 1990, 55, 203-222. (d) Winum, J.-Y.; Toupet, L.; Barragan, V.; Dewynter, G.; Montero, J.-L. A New Sulfamoylating Agent. Structure and Reactivity towards Amines. Org. Lett. 2001, 3, 2241-2243. For preparations of $N$-substituted sulfamides by reacting an amine with unsubstituted sulfamide, see: (e) McManus, J. M.; McFarland, J. W.; Gerber, C. F.; McLamore, W. M.; Laubach G. D. Sulfamylurea Hypoglycemic Agents. I. Synthesis and Screening. J. Med. Chem. 1965, 8, 766-776. (f) Aeberli, P.; Gogerty, J.; Houlihan, W. J. Neuropharmacological Investigations of $N$-benzylsulfamides. J. Med. Chem. 1967, 10, 636-642.

${ }^{12}$ For a pioneering example of sequential addition of two alkylamines to sulfuryl chloride, see: (a) Vandi, A.; Moeller, T.; Audrieth, L. F. Synthesis and Properties of Some N-Substituted Sulfamides. J. Org. Chem. 1961, 1136-1138. For a recent example involving sulfuryldiimidazole electrophiles, see: (b) Beaudoin, S.; Kinsey, K. E.; Burns, J. F. Preparation of Unsymmetrical Sulfonylureas from N,N'-Sulfuryldiimidazoles. J. Org. Chem. 2003, 68, 115-119. For examples involving catechol sulfate electrophiles, see: (c) Lee, C. H.; Lee, M. S.; Lee, Y.-H.; Chung, B. Y. Studies on the Synthesis and Chemical Properties of 1,2,5-Thiadiasolidine-3-one 1,1,-Dioxide Derivatives: Synthesis of $N$ Alkylsulfamides by Cleavage Reactions of $N$-(4-Methoxybenzyl)- and $N$-(3,4,-Dimethoxybenzyl)- $N$ '-alkylsulfamides with Trifluoroacetic Acid. Bull. Korean Chem. Soc., 1992, 13, 357. (d) Ballester Rodes, M.; Palomo Nicolau, F. E.; Palomo Coll, A. L. Preparation of Pure Sulfamide. Spanish Patent 2,006,778, Apr 7, 1989.

${ }^{13}$ (a) Blackburn, J. M.; Short, M. A.; Castanheiro, T.; Ayer, S. K.; Muellers, T. D.; Roizen, J. L. Synthesis of $N$ substituted Sulfamate Esters from Sulfamic Acid Salts by Activation with Triphenylphosphine Ditriflate. Org. Lett. 2017, 19, 6012-6015. (b) Shehata, M. F.; Short, M. A.; Sanders, M.; Roizen, J. L. Efficient synthesis of unsymmetrical sulfamides from sulfamic acid salts by activation with triphenylphosphine ditriflate. Tetrahedron 2019, 75, 31863194 discloses the following approach.

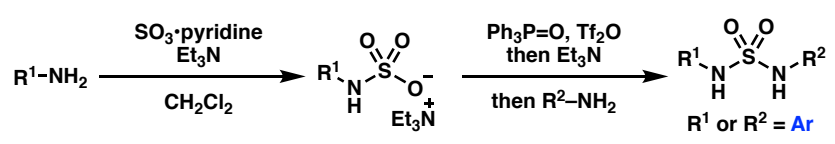


${ }^{14}$ Won, S.-Y.; Kim, S.-E.; Kwon, Y.-J.; Ham, J.; Kim, W-S. Chan-Lam coupling reaction of sulfamoyl azides with arylboronic acids for synthesis of unsymmetrical $N$-arylsulfamides. RSC Adv. 2019, 9, 2493-2497.

${ }^{15}$ For initial reports disclosing the Buchwald-Hartwig amination reactions, see: (a) Louie, J.; Hartwig, J. F. PalladiumCatalyzed Synthesis of Arylamines from aryl Halides. Mechanistic Studies Lead to Coupling in the Absence of Tin Reagents. Tetrahedron Lett. 1995, 36, 3609-3612. (b) Guram, A. S.; Rennels, R. A.; Buchwald, S. L. A Simple Catalytic Method for the Conversion of Aryl Bromides to Arylamines. Angew. Chem. Int. Ed. 1995, 34, 1348-1350.

${ }^{16}$ For pioneering reports describing the use of sulfamides in palladium-mediated $\mathrm{C}-\mathrm{N}$ bond-forming processes, see: (a) Alcaraz, L.; Bennion, C.; Morris, J.; Meghani, P.; Thom, S. M. Novel $N$-Aryl and $N$-Heteroaryl Sulfamide Synthesis via Palladium Cross Coupling. Org. Lett. 2004, 6, 2705-2708. (b) Muñiz, K.; Nieger, M. Sulfamide synthesis via Pd-catalysed cross-coupling. Synlett 2005, 2005, 149-151.

${ }^{17}$ For a review of applications of palladium-catalyzed C-N cross-coupling reactions, see: Ruiz-Castillo, P.; Buchwald, S. L. Applications of palladium-catalyzed C-N cross-coupling reactions. Chem. Rev. 2016, 116, 12564-12649.

${ }^{18}$ (a) Corcoran, E. B.; Pirnot, M. T.; Lin, S.; Dreher, S. D.; DiRocco, D. A.; Davies, I. W.; Buchwald, S. L.; MacMillan, D. W. C. Aryl Amination Using Ligand-Free Ni(II) Salts and Photoredox Catalysis. Science 2016, 353, 279-283. (b) Oderinde, M. S.; Jones, N. H.; Juneau, A.; Frenette, M.; Aquila B.; Tentarelli, S.; Robbins, D. W.; Johannes, J. W. Highly Chemoselective Iridium Photoredox and Nickel Catalysis for the Cross-Coupling of Primary Aryl Amines with Aryl Halides. Angew. Chem. Int. Ed. 2016, 55, 13219-13223. (c) Key, R. J.; Vannucci, A. K. Nickel Dual Photoredox Catalysis for the Synthesis of Aryl Amines. Organometallics 2018, 37, 1468-1472. (d) Kim, T.; McCarver, S. J.; Lee, C.; MacMillan, D. W. C. Sulfonamidation of Aryl and Heteroaryl Halides through Photosensitized Nickel Catalysis. Angew. Chem. Int. Ed. 2018, 57, 3488-3452. (e) Reddy, L. R.; Kotturi, S.; Waman, Y.; Reddy, V. R.; Patel, C.; Kobarne, A.; Kuttappan, S.; N-Arylation of Carbamates through Photosensitized Nickel Catalysis. J. Org. Chem. 2018, 83, 13854-13860. (f) Koney, M. O.; McTeague, T. A.; Johannes, J. W. NickelCatalyzed Photoredox-Mediated Cross-Coupling of Aryl Electrophiles and Aryl Azides. ACS Catal. 2018, 8, 91209124.

${ }^{19}$ Sulfamate esters react efficiently under photochemically-driven, nickel-mediated reaction conditions, but not under most palladium-mediated protocols. For details, see: Blackburn, J. M.; Kanegusuku, A. L. G.; Scott, G. E.; Roizen, J. L. Photochemically-Mediated, Nickel-Catalyzed Synthesis of $N$-(Hetero)aryl Sulfamate Esters. Org. Lett., 2019, 21, 7049-7054. 
${ }^{20}$ Qiu, J.; Albrecht, J. Solubility Correlations of Common Organic Solvents. Org. Process Res. Dev. 2018, 22, 829835.

${ }^{21}$ (a) Laulhé, S.; Blackburn, J. M.; Roizen, J. L. Selective and Serial Suzuki-Miyaura Reactions of Polychlorinated Aromatics with Alkyl Pinacol Boronic Esters. Org. Lett. 2016, 18, 4440-4443. (b) Laulhé, S.; Blackburn, J. M.;

Roizen, J. L. Exhaustive Suzuki-Miyaura Reactions of Polyhalogenated Heteroarenes with Alkyl Boronic Pinacol

Esters. Chem. Commun. 2017, 53, 7270-7273. (c) Blackburn, J. M.; Roizen, J. L. Catalytic Strategies to Convert 2Halopyridines to 2-Alkylpyridines. Asian J. Org. Chem. 2019, 8, 920-930.

${ }^{22}$ McDermott, S. D.; Burke, P. O.; Spillane, W. J. Basicity of nitrogen-sulphur(VI) compounds. Part 5. Ionization of trisubstituted sulphamides. J. Chem. Soc., Perkin. Trans. 2. 1984, 499-502.

${ }^{23}$ Wheeler, K. W.; Degering, E. F. Preparation and Properties of Certain Derivatives of Sulfamide. J. Am. Chem. Soc. 1944, 66, 1242-1243.

${ }^{24}$ For pioneering reports, see (a) Liebeskind, L. S.; Srogl, J. Thiol Ester-Boronic Acid Coupling. A Mechanistically Unprecedented and General Ketone Synthesis. J. Am. Chem. Soc. 2000, 122, 11260-11261. (b) Liebeskind, L. S.; Srogl, J. Heteroaromatic Thioether-Boronic Acid Cross-Coupling under Neutral Conditions. Org. Lett. 2002, 4, 979981. For reviews, see: (c) Prokopcova, H.; Kappe, C. O. The' Liebeskind-Srogl C-C Cross-Coupling Reaction. Angew. Chem., Int. Ed. 2009, 48, 2276-2286. (d) Cheng, H.-G.; Chen, H.; Liu, Y.; Zhou, Q. The Liebeskind-Srogl Cross-Coupling Reaction and Its Synthetic Applications. Asian J. Org. Chem. 2018, 7, 490-508.

${ }^{25}$ Cherkasov, V. M.; Dashevskaya, T. A.; Baranova, L. I. Reaction of $N, N$-dichlorosulfonamides with aryl isothiocyanates. Chem. Heterocyl. Comp. 1969, 5, 127-128.

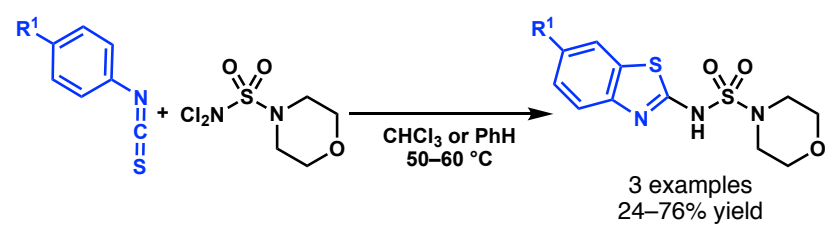

${ }^{26}$ By definition, the "production step" is a transformation that allows for ready installation of related but varied molecular components, such as aryl groups, on a single functional group handle, such as a sulfamide, to generate a focused yet diverse small molecule library.

${ }^{27}$ Crampton, R. H.; Fox, M.; Woodward, S. N-(Alkylsulfamoyl)aldimines: easily deprotected precursors for diarylmethylamine synthesis. Tetrahedron: Asymmetry. 2013, 24, 599-605. 
${ }^{28}$ Li, J.; Minnaard, A.J.; Klein Gebbink, R.J.M.; van Koten, G. P'CP'-Pincer palladium complex-catalyzed allylation of N,N-dimethylsulfamoyl-protected aldimines. Tet. Lett. 2009, 50, 2232-2235.

${ }^{29}$ Feng, X.; Guan, H,; Kan, Y.; Ioannidis, S.; Peng, B.; Su, M.; Wang, B.; Wang, T.; Zhang, H-J. 4- (3-aminopyrazole) pyrimidine derivatives for use as tyrosine kinase inhibitors in the treatment of cancer. World IP Organization WO2007049041. 03 May 2007.

${ }^{30}$ Espino, C. G.; Wehn, P. M.; Du Bois, J. Synthesis of 1,3-Difunctionalized Amine Derivatives through Selective CH Bond Oxidation. J. Am. Chem. Soc. 2001, 123, 6935-6936.

${ }^{31}$ Rikimaru, K.; Wakabayashi, T.; Abe, H.; Tawaraishi, T.; Imoto, H.; Yonemori, J.; Hirose, H.; Murase, K.; Matsuo, T.; Mastumoto, M.; Nomura, C.; Tsuge, H.; Arimura, N.; Kawakami,1 K.; Sakamoto, J.; Funami,; M.; Mol, C.D.; Snell, G.P.; Bragstad, K.A.; Sang, B.-C.; Dougan, D.R.; Tanaka, T.; Katayama, N.; Horiguchi, Y.; Momose, Y. Structure-activity relationships and key structural features of pyridyloxybenzene-acylsulfoneamides as new, potent, and selective peroxisome proliferator-activated receptor (PPAR) $\gamma$ Agonists. Bioorg. Med. Chem. 2012, 20, 332-3358.

${ }^{32}$ Valerio, V.; Petkova, D.; Madelaine, C.; Maulide, N. Direct Room-Temperature Lactonisation of Alcohols and Ethers onto Amides: An “Amide Strategy” for Synthesis. Chemistry: A European Journal. 2013, 19, $2606-2610$.

${ }^{33}$ Fier, P.S.; Luo, J.; Hartwig, J.F. Copper-Mediated Fluorination of Arylboronate Esters. Identification of a Copper(III) Fluoride Complex. J. Am. Chem. Soc. 2013, 135, 2552-2559. 